\title{
IMPACT OF THE USE OF PRODUCE \\ GROWN IN AN ELEMENTARY SCHOOL GARDEN \\ ON CONSUMPTION OF VEGETABLES \\ AT SCHOOL LUNCH
}

\author{
by \\ James V. DiDomenico, III
}

A thesis submitted to the Faculty of the University of Delaware in partial fulfillment of the requirements for the degree of Master of Science in Human Nutrition.

Fall 2009

Copyright 2009 James V. DiDomenico, III

All Rights Reserved 


\title{
IMPACT OF THE USE OF PRODUCE GROWN IN AN ELEMENTARY SCHOOL GARDEN ON CONSUMPTION OF VEGETABLES AT SCHOOL LUNCH
}

\author{
by \\ James V. DiDomenico, III
}

Approved:

Nancy Cotugna, DrPH, RD, LDN

Professor in charge of thesis on behalf of the Advisory Committee

Approved:

Susan J. Hall, $\mathrm{PhD}$

Chair of the Department of Health, Nutrition, and Exercise Sciences

Approved:

Kathleen S. Matt, PhD

Dean of the College of Health Sciences

Approved:

Debra H. Norris, MS

Vice Provost for Graduate and Professional Education 


\section{ACKNOWLEDGMENTS}

Nancy Cotugna, DrPH, RD, LDN for her continuing support and guidance as my adviser during this project.

Carolyn Manning, MAg, RD, LDN for her support and guidance as a committee member.

Thianda Manzara, PhD for her support and guidance as a committee member and as the director of Healthy Foods for Healthy Kids, Inc.

The administration, faculty, and cafeteria staff at Maclary Elementary School, Marshall Elementary School, and Keene Elementary School for hosting the study. 


\section{TABLE OF CONTENTS}

LIST OF TABLES ...................................................................................... vii

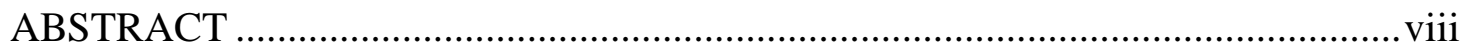

\section{CHAPTER}

1. Introduction and Literature Review ........................................................ 1

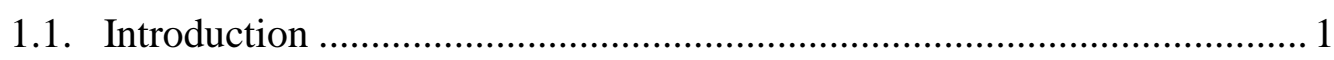

1.1.1. Fruit and Vegetable Consumption.......................................... 2

1.1.2. National School Lunch Program .............................................. 2

1.2. Literature Review ............................................................................ 3

1.2.1. School Fruit and Vegetable Education ........................................ 3

1.2.2. School Garden Programs ............................................................... 4

1.2.2.1. School Gardens as Educational Tools .......................... 4

1.2.2.2. School Garden Programs and Vegetable Preferences................................................................... 5

1.2.2.3. School Gardens and the School Lunch Program .............. 6

1.2.3. Conclusion............................................................................... 7

1.3. Partner Organizations .................................................................. 7

1.3.1. Healthy Foods for Healthy Kids, Inc....................................... 7

1.3.2. Child Nutrition Services of Christina School District.................. 8

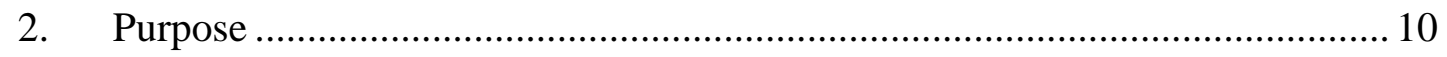

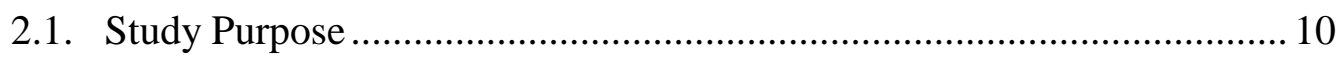

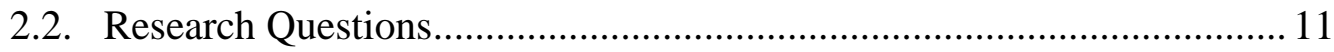

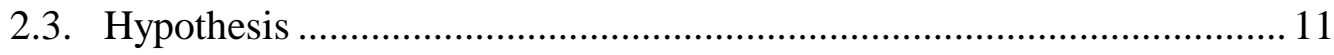

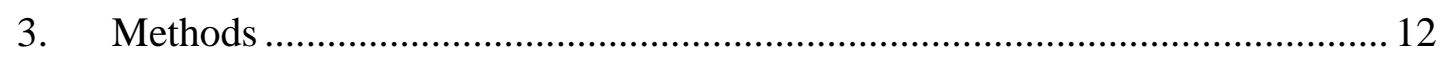

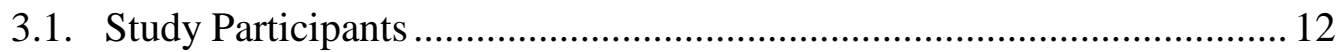

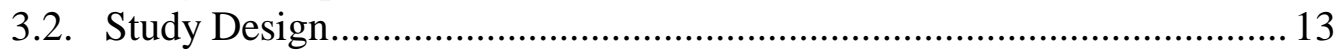

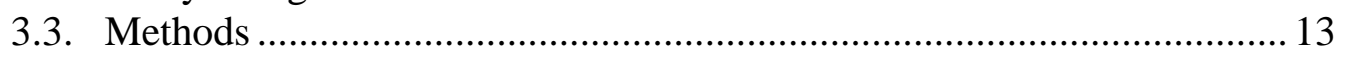

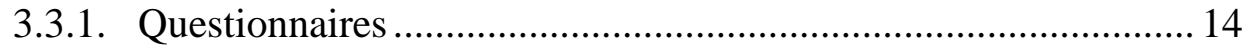

3.3.1.1. Development and Validation ..................................... 14 
3.3.1.2. Demographic Questions ......................................... 15

3.3.1.3. Vegetable Preference Questions ................................ 15

3.3.1.4. Vegetable Consumption Questions ............................ 16

3.3.1.5. Questionnaire Administration ................................... 16

3.3.2. Cafeteria Observations ........................................................ 16

3.3.2.1. Observation Procedure ............................................... 17

3.3.2.2. Observation Design .................................................. 17

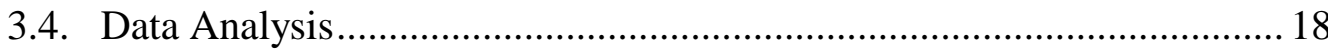

3.4.1. Questionnaire Data Analysis .................................................... 19

3.4.2. Observation Data Analysis ................................................... 20

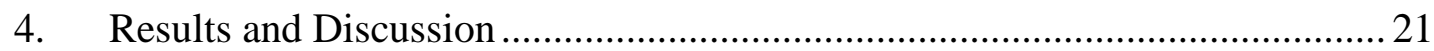

4.1. Demographic Characteristics of Sample ........................................... 21

4.1.1. Questionnaire samples ........................................................ 22

4.1.2. Observation sample ............................................................. 23

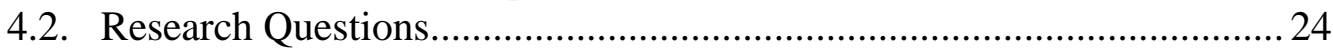

4.2.1. Research Question 1 ......................................................... 24

4.2.1.1. Questionnaire Question 5 ....................................... 25

4.2.1.1.1. Questionnaire Results ............................. 25

4.2.1.1.2. Discussion.............................................. 26

4.2.1.2. Questionnaire Question 9 .......................................... 27

4.2.1.2.1. Pre-program Questionnaire....................... 27

4.2.1.2.2. Discussion............................................... 27

4.2.1.3. Questionnaire Question 10 ...................................... 29

4.2.1.3.1. Questionnaire Results .............................. 29

4.2.1.3.2. Discussion.............................................. 31

4.2.1.4. Questionnaire Question 11 ........................................ 31

4.2.1.4.1. Questionnaire Results ................................ 33

4.2.1.4.2. Discussion.................................................. 33

4.2.1.5. Conclusions for Research Question 1........................ 33

4.2.2. Research Question 2 .............................................................. 34

4.2.3. Research Question 3 ............................................................. 35

4.2.4. Research Question 4 ............................................................. 36

4.2.4.1. Observation One ..................................................... 37

4.2.4.2. Observation Two .......................................................... 38

4.2.4.3. Observation Three ...................................................... 40

4.2.4.4. Discussion ............................................................... 40

4.2.5. Research Question 5 ............................................................. 41

4.2.6. Research Question 6 ........................................................... 42

4.2.6.1. Gender ............................................................. 42

4.2.6.2. Race …....................................................... 43 
4.2.6.3. Hispanic Ethnicity 44

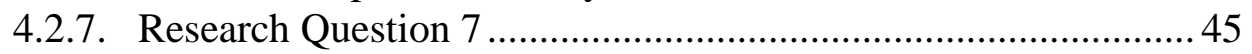

4.3. Limitations and Recommendations for Future Research........................... 47

4.3.1. Threats to Internal Validity......................................................... 47

4.3.2. Threats to External Validity …………………………………........ 48

4.3.3. Other Limitations.......................................................................... 49

4.3.4. Conclusions on Limitations .......................................................... 49

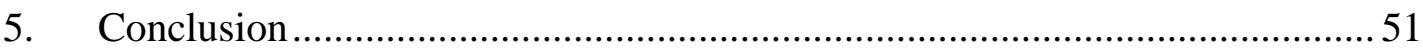

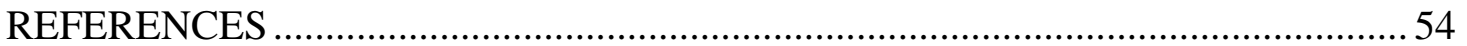

APPENDIX

A. Human Subjects Board Review ………………………………………….... 57

B. Pre- and Post-Program Questionnaire ……………………………................ 59 


\section{LIST OF TABLES}

Table 3.1. Treatment Groups ............................................................................... 13

Table 3.2. Source of salad ingredients for cafeteria observations............................. 18

Table 4.1. Demographic Characteristics of Sample Group....................................... 22

Table 4.2. Demographic characteristics of survey respondents.................................. 23

Table 4.3. Estimate of the Number of Common Vegetables ${ }^{\mathrm{a}}$ Which School Children Enjoy Eating (Like Score) Before and After Participation a School Gardening Program.................................................................. 26

Table 4.4. Frequency of Enjoying Eating Vegetables Before and After Participation in a School Garden Program .............................................. 28

Table 4.5. Frequency of Children's Trying New Vegetables If Offered Before and After Participation in a School Gardening Program.......................... 30

Table 4.6. Would Children Give Vegetables They Did Not Like Another Try After Participating in a School Garden Program? ..................................... 32

Table 4.7. Estimate of the Number of Common Vegetables ${ }^{\mathrm{a}}$ That School Children Have Tasted (Taste Score) Before and After Participation a School Gardening Program.

Table 4.8 Number of Times per Week School Children Consume Vegetables at School Lunch Before and After Participation in a School Garden Program

Table 4.9. Observation of School Lunch to Determine If Using School Garden Produce in School Lunch Has an Effect Upon Children's Food Choices

Table 4.10. Gender Differences Between Children When Asked If They Would Be More Likely to Eat a Vegetable At School Lunch When It Was Grown in the School Garden 


\begin{abstract}
Low consumption of nutrient- and fiber-rich fruits and vegetables has been implicated in the increase in childhood obesity seen over the past two decades. The use of school gardens is a new nutrition education method that may provide some additional benefit in getting children to consume the recommended amount of vegetables. Previous research into the effectiveness of school gardens has shown that they have positive impacts upon children's vegetable preferences, and they can have a positive impact on children's consumption of vegetables at school lunch. However, no research has examined using school garden produce at school lunch to determine if that tactic would have an additional impact on children's consumption of vegetables at school lunch.

In this study, a school garden program in Delaware was evaluated for its impact upon program participants’ vegetable preferences and consumption of vegetables at school lunch. This study used a quasi-experimental design to examine 252 fourth- and fifth-graders in two schools that have been participating in the garden program and 107 fourth- and fifth-graders in a nearby school that does not have a school garden, as a control group. An 11-item questionnaire was used to examine participants’ vegetable preferences and a series of cafeteria observations was completed to determine if using garden produce as the vegetable offering in the school cafeteria leads children to choose to eat that vegetable.

Results showed that participants in the school garden program were more willing to try new vegetables after having participated in the program $(p=0.01)$. Although this study did not find that participation in the school garden program
\end{abstract}


increased the amount of vegetables the participants consumed at school lunch, it did find that using school garden produce as a hook to get children who have worked in the garden to consume that produce at school lunch is a successful tactic to promote vegetable consumption $(p<0.05)$. Not surprisingly, the study also found that those participants who already gardened outside of school was positively correlated with consuming vegetables at school lunch, with those gardening outside of school consuming vegetables $1.04 \pm 0.40$ times per week more $(p=0.009)$ supporting existing research which shows that participating in a gardening program has a positive impact on vegetable consumption.

In conclusion, participation in a school gardening program does have a small positive impact upon children's vegetable preferences and consumption levels. The knowledge gained from this research can be used to increase the effectiveness of school garden programs to promote vegetable consumption among children. 


\section{Chapter 1}

\section{INTRODUCTION AND LITERATURE REVIEW}

\subsection{Introduction}

Childhood obesity is at an historic high and still rising (1). Data from the National Health and Nutrition Examination Surveys show that the prevalence of obesity in children 6-to 11-years-old has increased from 6.5\% in the period 1976-1980 to $17 \%$ in $2003-2006$ (2). This rise in obesity has been linked to the rise of other health concerns in children, including cardiovascular disease (3), asthma (4), sleep apnea (5), and type 2 diabetes (6). The rise in obesity is such a public health concern that the United States Department of Health and Human Services, in its Healthy People 2010 report, has identified reducing the proportion of children ages 6-to 11-years-old who are overweight or obese to $5 \%$ of the population as an objective towards the goal of increasing the quality and years of life of the people of the United States (7). However, the Healthy People 2010 Midcourse Report has reported that the country is moving away from the 5\% target (8).

Several factors have been identified as contributors to the rise in obesity, including both behavioral and environmental factors. The consumption of calorierich, nutrient- and fiber-poor foods instead of fresh produce combined with lower levels of physical activity are among the behavioral factors, while environmental factors include time in school spent engaging in physical activity, food available for students in schools, and access to affordable healthy foods (9). 


\subsubsection{Fruit and Vegetable Consumption}

Lower than recommended consumption of nutrient- and fiber-rich vegetables is one factor implicated in the increasing prevalence of obesity. The Produce for a Better Health Foundation reported that males 9- to 13-years old consume only 1.5 cups of vegetables per day, and females of the same age range consume only 1.4 cups of vegetables per day, excluding nutrient-poor and calorie-rich potato chips and French fries (10). The 2005 Dietary Guidelines for Americans, however, recommend 2.0 cups for males and 2.5 cups for females for moderately active children of the same age range (11). Children 9- to 13-years old should be eating more vegetables than they currently do. Furthermore, children of that age range eat especially low amounts of nutrient-rich dark green and orange vegetables (12). There is thus much room for improvement in the dietary habits of American children.

Children spend a large part of their time outside of the home in school, and so schools have been identified as a site where nutrition education could have some impact upon their dietary habits (13). Furthermore, since more than half of American elementary, middle, and high school students eat at least one meal at school on a daily basis, school feeding programs are an excellent time to encourage healthy dietary choices (12).

\subsubsection{National School Lunch Program}

The school lunch environment has been suggested as a site that can be integrated with health education programs operating independently within the school to promote the consumption of nutrient-dense foods (14). Food consumed at school has been found to account for over $35 \%$ of calories consumed by elementary school 
students (15). There is thus a great opportunity to use food consumed at school to teach children the importance of consuming fruits and vegetables.

The Third School Nutrition Dietary Assessment Study (SNDAS), conducted in the 2004-05 academic year, reported that while $88 \pm 2 \%$ of schools where the National School Lunch Program (NSLP) is operating offered vegetables other than French fries at school lunch, only $31.6 \pm 3.0 \%$ of elementary school students in those schools consumed those vegetables, amounting to an average consumption for all students of $0.1 \pm 0.01$ cup-equivalents of vegetables per day at school lunch (15). Lettuce salads (the vegetable used in this study) performed even worse in the SNDAS, with $34 \%$ of NSLP schools offering them, and only $7 \%$ of students consuming them (16). So, while schools offer vegetables as a healthy choice for school lunch, not many students are choosing to include vegetables in their lunches.

\subsection{Literature Review}

Because children spend so much time in school, nutrition education in children has focused on educating within the school environment. School gardens are a relatively new educational tool for impacting children's food habits and preferences. While there has been a copious amount of research on traditional nutrition education practices, the effect of school gardens used for nutrition education is a new branch of nutrition education research, and so research on school gardens is only beginning to appear.

\subsubsection{School Fruit and Vegetable Education}

There is some evidence that students pick up eating behaviors from their environment, so schools may be effective sites for nutrition education. A meta- 
analysis conducted by Howerton et al. (13) looked at the published evaluations of seven nutrition education programs, including data from the evaluation of 8156 7-to 12-year-olds, to see if fruit and vegetable consumption increased after a school-based nutrition education program. Five of the studies used 24-hour recalls, three plate waste, two an observation, and two a survey or questionnaire to determine the change in fruit and vegetable consumption. The analysis revealed a 19\% increase in consumption of fruit and vegetables relative to controls $(p<0.001)$ pooled across all 8156 youths, when measured by the relative change in each study, thus accounting for differences in the study populations. So, traditional nutrition education can produce a positive change in students' eating habits. However, are there other educational tools that can make nutrition education even more effective? School gardens may be a useful way to make further increases in children's eating habits.

\subsubsection{School Gardening Programs}

Research on the effects of school gardens in the United States just began to appear in 2001. The research on school gardens suggests that school gardens improve students' knowledge about vegetables grown in the garden by increasing students' exposure to them. Also, students are encouraged to taste vegetables from the garden by the model behavior of adventurous peers.

\subsubsection{School Gardens as Educational Tools}

Until recently, educational gardens were not often found on school grounds in the United States. The state of California is considered to be the leader in school gardens, since the "A Garden in Every School” initiative was launched in the late 1990s. Graham et al. (17) reported that the proportion of California public 
schools with gardens has increased from 13\% in 1996 to 24\% in 2005. Gardens were most effective in elementary schools as a resource in science (86\% of elementary schools), environmental science (64\%), and nutrition education (63\%). However, 55\% of all schools did not find the gardens effective at influencing the school meal program (17). This may be because the logistical issues involved with growing enough produce to use in the school cafeteria might have scared the schools away from using the garden for this purpose.

\subsubsection{School Garden Programs and Vegetable Preferences}

As new research is published on gardening programs, it is possible to determine how much of an impact garden programs can have on people’s food preferences and habits. Alaimo et al. (18) reported that households who participate in community gardens were 3.5 times as likely $(p<0.05)$ to consume at least 5 servings of fruit and vegetables per day. So, participation in gardening programs does seem to increase preference for fruit and vegetables. Other research illuminates why gardening programs might have this effect.

It may be that garden activity increases primarily the self-efficacy of participants. A survey conducted on first-graders reported that 47 students who were undergoing a nutrition education program with a gardening component were more willing to taste vegetables than 49 control students (4.83 vs. 4.07 on a 1-to-5 scale, $p<$ 0.005) (19). Another study of 122 sixth-grade students examined the effect of the school garden component, independent of nutrition education (20). Daily consumption of vegetables was unchanged in the control school, with no nutrition education or gardening, and in the first experimental school, with nutrition education but no gardening; however, in the second experimental school, with both nutrition 
education and gardening vegetable consumption increased from 1.2 servings per day to 2.6 servings per day $(p<0.001)$, when measured by the 24 -hour recall method $(20)$. In this study, the standard nutrition education provided students the knowledge necessary to make a dietary change, while the gardening activities increased the self-efficacy of the students by providing them with extra exposure to the foods they would have to eat to make a dietary change.

Schools are also excellent places to encourage children to engage in physical activity. However, students’ physical activity levels are declining in schools because of the cutbacks of physical education and recess time periods (21). School gardens are a way in which schools can increase the physical activity level of their students while also using the time and space for instruction in other disciplines, including health, science, art, social studies, and mathematics.

\subsubsection{School Gardens and the School Lunch Program}

Parmer, et al. (22) reported that after a nutrition education program containing a gardening component, second-graders were more likely to choose a vegetable at school lunch than students who participated in traditional nutrition education alone or in the control group. In the nutrition education with gardening group, choosing a vegetable at school lunch increased from pre-test to post-test by $55 \%(p<0.01)$, while students in the nutrition education alone group $(p=0.08)$ and control group ( $p=0.47)$ failed to show a significant change.

The results of this study may be somewhat biased, as the convenience sample was “predominately white” (participants’ exact racial distribution was not reported) and $70 \%$ male. Also, while this study did examine the effect of gardening education on students' choices at school lunch, the researchers did not attempt to use 
the vegetables grown in the school garden in the school's cafeteria. No studies have been found examining the effect of programs that use school garden produce in their food service program.

\subsubsection{Conclusion}

The research shows an increase in vegetable preference among participants in nutrition education programs with a garden component. Consequently, the American Dietetic Association, the Society for Nutrition Education, and the American School Food Service Association have recommended the use of school gardens as a useful nutrition education strategy (23). Furthermore, using school garden produce in school food service programs has been suggested as a means to improve the nutritional quality of food served at school lunch, integrate food service with nutrition education, and possibly reduce the cost of school lunches $(17,18)$.

\subsection{Partner Organizations}

Two community organizations were partnered with to complete this research. Healthy Foods for Healthy Kids, Inc. (HFHK) constructed and ran the school gardens and implemented the educational programming. Child Nutrition Services of the Christina School District prepared and served the garden produce and allowed the observation of their food service line.

\subsubsection{Healthy Foods for Healthy Kids, Inc.}

The non-profit organization HFHK assists schools in establishing vegetable garden-based education programs. The first HFHK program was started in 2004 at Springer Middle School, in Delaware’s Brandywine School District. HFHK has recently partnered with Child Nutrition Services of the Christina School District to 
create the Education Cultivation (EC) garden-based education program operating in the elementary schools of Christina School District. HFHK is independent from the districts it serves and is privately funded, and the gardening program it offers is integrated into the science curricula at each of the schools in which it operates.

The lessons offered by HFHK center around the schoolyard garden at each school in which it operates. The goal of the program is that through students' experiences in the garden and tasting the produce, students will increase their knowledge about food and nutrition and will increase their self-efficacy in adopting healthy eating habits, all while providing an engaging, active-learning environment for students. HFHK's nutrition education and gardening program is comprised of classroom education, garden activities, and garden produce tastings. However, the participants in this study only harvested vegetables from the garden and tasted garden vegetables.

\subsubsection{Child Nutrition Services of Christina School District}

Child Nutrition Services is the foodservice arm of Christina School District, located in northwestern New Castle County, Delaware. Students in the District are offered a choice of meal components for lunch. Students who are eligible to receive a free- or reduced-cost lunch from NSLP must choose foods from at least three of the five food groups offered by the district: a protein, a starch, a fruit, a vegetable, and a milk beverage. Students may choose foods from more than three groups, but they must choose foods from at least three. Non-NSLP-eligible students may purchase an NSLP lunch at full cost (currently \$3), or may purchase food à la carte from the cafeteria (side salads with dressing were offered at \$0.75). Thus, not all students are required to have a vegetable as part of their lunch every day. The menus 
in the District are prepared by a registered dietitian and are consistent across all schools in the District, so each child has access to the same choices each day. 


\section{Chapter 2}

\section{PURPOSE}

\subsection{Study Purpose}

The purpose of this study was to evaluate the effect the garden component

of a gardening education program, EC, had upon the preferences for and consumption of vegetables, especially vegetables grown on site by elementary school students, and offered during the school lunch program. Although there have been several studies published examining the link between school gardens and children’s vegetable preferences $(17-20,22,24)$, no studies have been found in the published literature examining the effect of using produce grown on site at the school garden in the school cafeteria. This research thus fills a gap in the current body of literature. Furthermore, this research examined if the garden component of the EC program model is an effective way to help address a stated public health objective of the United States; specifically, it addressed the objective of increasing the proportion of Americans who consume at least three servings of vegetables daily.

HFHK will use the data collected in this study to evaluate the effectiveness of the EC program and plan for its refinement and expansion. Study expenses have been funded by Child Nutrition Services of the Christina School District and Healthy Foods for Healthy Kids. 


\subsection{Research Questions}

1. How does participation in the garden component of the EC program influence children's vegetable preferences?

2. Did students participating in the gardening component of the EC program taste new vegetables that they had not previously eaten?

3. How does participation in the gardening component of the EC program influence students' consumption of the vegetable offering at school lunch?

4. Does the fact that the vegetable offered at school lunch is grown in the school garden by students and their peers influence students' choice to consume or not consume the vegetable?

5. What importance does repeated exposure of the students to the gardening component of the EC program have upon students' consumption of vegetables at School Lunch?

6. Do children's gender, race, and Hispanic status have an effect on their preferences for vegetables?

7. How does gardening experience outside the EC program affect children's preferences for vegetables and willingness to try new vegetables?

\subsection{Hypothesis}

By participating in the gardening component of the EC program, students will taste new vegetables and increase their preferences for vegetables. Furthermore, offering school garden produce at school lunch will increase the proportion of students who choose a vegetable as a part of their school lunch. 


\section{Chapter 3}

\section{METHODS}

\subsection{Study Participants}

Study participants included fourth and fifth grade students at three

elementary schools in Christina School District: William B. Keene Elementary School, Thurgood Marshall Elementary School, and R. Elizabeth Maclary Elementary School. Keene and Marshall participated in the EC program during the study and have school gardens on their campuses. A total of 359 students were invited to participate in the study.

These participants were chosen because all three schools had similar demographics, especially with respect to Hispanic ethnicity and low-income status. It was thought that these two demographic factors would have had the greatest impact upon the students' vegetable preferences because of differences in food consumed outside the school, especially at home.

Human subjects review exemption was obtained from the University of Delaware Human Subjects Review Board. A letter was sent home to parents describing the research program and allowing the parent to opt-out. The exemption letter and the consent letter are provided in Appendix A. 


\subsection{Study Design}

This study had a quasi-experimental design, with pre- and post-program measurements with one control group and two treatment groups. The fourth and fifth grade classes at Maclary Elementary School comprise the control group, and were not chosen randomly, but based on similar demographics to the treatment groups. The two treatment groups were included to determine the effect of a second exposure to the program. For one treatment group, the fourth grade at Marshall Elementary School, the time period in which the study operated was the students' first exposure to the EC program. Students at Keene Elementary School, the second treatment group, were undergoing the program a second time. The treatment groups are summarized in Table 3.1.

Table 3.1. Treatment Groups

\begin{tabular}{|l|l|l|c|}
\hline & $\begin{array}{l}\text { Maclary } \\
\text { Elementary School }\end{array}$ & $\begin{array}{l}\text { Marshall } \\
\text { Elementary School }\end{array}$ & $\begin{array}{l}\text { Keene Elementary } \\
\text { School }\end{array}$ \\
\hline Program Exposures & 0 & 1 & 2 \\
\hline
\end{tabular}

No school garden was present at Maclary Elementary School during the study.

\subsection{Methods}

Study participants harvested vegetables from the school garden that were planted and tended by other students who did not participate in the study. Study participants harvested garden produce twice; however, only produce from one of the harvests was used for the cafeteria observations. The garden vegetables that were grown and harvested included lettuce, spinach, arugula, radishes, and turnips. 
Participants’ preferences towards vegetables were measured by use of questionnaires developed for this study. Participants' consumption of vegetables at school lunch was measured by observing what foods participants chose in the cafeteria service line.

Robinson-O’Brien, et al. (24) proposed evaluation methodologies to effectively evaluate the effectiveness of nutrition education programs. This study used several of those methodologies, including pilot testing the survey tool and having sample sizes large enough to evaluate the independent impact of gender and cultural group. It also used control groups and attempted to track whether students change their attitudes towards and intakes of vegetables alter over time.

\subsubsection{Questionnaires}

An 11-item questionnaire used for both pre-program and post-program data collection to determine participants' preferences for vegetables and whether participants gardened outside of school. The full version of the 11-item instrument is included in Appendix B and asked four types of questions:

1. demographic

2. vegetable preference questions

3. vegetable consumption questions

4. a question about gardening outside school.

\subsubsection{Development and Validation}

The questionnaire was adapted from a previous instrument used by HFHK for informal evaluation of school gardening programs. Questions were selected from that instrument for inclusion based on whether they addressed the research questions. 
Also, questions were added to the instrument to address the research questions that the original instrument did not.

The questionnaire was validated for content by 4 nutrition and school gardening professionals before also being pilot tested for clarity with a group of 18 fourth grade students. As a result of the validation and pilot testing, 2 questions were reworded and the list of common vegetables for questions 4 and 5 was amended to include another vegetable supplied by the pilot test group.

\subsubsection{Demographic Questions}

The first three questions of the questionnaire addressed participants’ demographics. Participants were asked to circle their gender and race, and they were also instructed to indicate whether they were of Hispanic ethnicity. For the race question, participants could write-in an answer if they did not identify with the choices provided.

\subsubsection{Vegetable Preference Questions}

For the fourth and fifth questions in the survey, participants were presented with a list of common vegetables. Participants were instructed to circle the names of vegetables that they had previously tasted (the fourth question) and vegetables that they enjoy eating (the fifth question). Space was provided to write-in another vegetable if the participant desired. While these two questions named specific vegetables, the last three questions (9 through 11) asked participants about their preferences for vegetables in general, using a 4-point, Likert-type scale. 


\subsubsection{Vegetable Consumption Questions}

Questions 6 and 7 addressed participants’ vegetable consumption habits. Question 6, the only numerical question on the instrument, asked participants to identify how many times per week they consumed any vegetable at school lunch, from 0 times (never) to 5 times (every day) per week. Question 7 asked participants if offering garden produce in the cafeteria would make him or her more or less likely to choose to eat a vegetable at school lunch, or if it would have no impact.

\subsubsection{Questionnaire Administration}

Identical versions of the questionnaire were administered to the participants in March 2009 (hereafter called “pre-program questionnaire”), before the beginning of involvement with the school garden, and in late May-June 2009 (hereafter called "post-program questionnaire”), after harvesting the garden produce. The participants’ normal classroom instructors administered the surveys, reading questions aloud, so that participants’ reading level would not affect their ability to answer the questionnaires. Pre-program and post-program questionnaires were not matched, so participants were not asked to supply any identifying information.

\subsubsection{Cafeteria Observations}

The participants were observed in the lunch line of the cafeteria three times throughout this study. These observations examined whether students chose a salad from the foods that were offered as part of the school lunch. The treatment groups were offered a salad made primarily from garden produce on one day, and during all other observations, the salad that was offered was made from non-local ingredients. On the days when school garden produce was offered in the cafeteria, a 
small letter-size sign was displayed advertizing to the children that the salads were made from school garden produce.

\subsubsection{Observation Procedure}

On the days that the participants were to be observed, the schools offered a small (3/4 cup) lettuce salad with dressing packets on the side. Observers included two community nutrition students and were trained by the primary researcher. Observers stood by the cash register at the end of the line and observed the foods participants left the line with. Participants who had left the line with a salad were tallied separately from participants who left the line without a salad. Observers were able to also observe both participants' behavior near the spot where they were able to pick up the salad, and also whether cafeteria staff encouraged participants to choose a salad.

\subsubsection{Observation Design}

Each group of participants was observed three times in the cafeteria. However, whether the salad that was offered was made from ingredients grown locally in the school garden or from non-local ingredients differed based on the participant group and the observation. Table 3.1 shows the source of the salad ingredients used for each observation. 
Table 3.2. Source of salad ingredients for cafeteria observations.

\begin{tabular}{|l|l|l|l|}
\hline School & Observation One & Observation Two & Observation Three \\
\hline Maclary & Purchased ingredients & Purchased ingredients & Purchased ingredients \\
\hline Marshall & Purchased ingredients & Purchased ingredients & Garden Produce \\
\hline Keene & Purchased ingredients & Purchased ingredients & Garden Produce \\
\hline
\end{tabular}

Observation one was the pre-program observation; its purpose was to establish a consumption baseline. Observations two and three were performed after participants had undergone the garden education program, with only observation three using garden produce (and only then with the treatment groups). A significant difference between observations one and two would suggest that the gardening experience had an effect on students' food choices. A significant difference between observations two and three would suggest that students' food choices were affected by using garden produce in the school foodservice program. Finally, a significant difference between observations one and three would suggest that a combination of the gardening program and the offering of garden produce in the cafeteria had an effect on students’ food choices.

\subsection{Data Analysis}

The statistics software package JMP (version 8.0.1, 2009, SAS Institute Inc, Cary, NC) was used to analyze the data. Descriptive and inferential statistics were computed for both questionnaire data and observation data. 


\subsubsection{Questionnaire Data Analysis}

Questionnaire data were coded and entered into the statistics software. For the two questions in which participants were instructed to circle the names of vegetables they had previously tasted and ones they enjoy eating, a Taste Score and a Like Score were computed by counting each vegetable the participants circled or wrote on the form from the list of 23 common vegetables. This scoring system allowed for an objective determination of participants’ preferences for vegetables as a group. Descriptive statistics and t-tests were performed on each score's data to determine whether, within each treatment group, participants’ preferences for vegetables had changed as a result of participation.

For question 6, in which participants were instructed to identify how many times per week they consume a vegetable at school lunch, descriptive statistics and ttests were computed on the data. The data were compared both within and among the treatment groups to determine if participation in the EC program had an effect. The rest of the non-demographic questions were analyzed with descriptive statistics and chi-square tests to determine if attitudes and behaviors with regard to vegetable consumption had changed as a result of participation in the program.

The demographic questions were analyzed by calculating the percentages for each response. Furthermore, cross tabulations and chi-square tests were used to compare data from other questions to the demographic survey questions (gender, race, and ethnicity) and the question asking if students garden at home to determine if any of the demographic variables were correlated with other survey data. 


\subsubsection{Observation Data Analysis}

Data collected from lunch observations addressed the question of whether students are more likely to choose the vegetable offering at school lunch having participated in the program, and/or knowing that the ingredients for the vegetable offering came from the school garden produce they had just harvested. The proportion of students taking a side salad in the lunch line was calculated, and difference of proportion tests were conducted within each school to determine whether students' lunch choices were affected by working in the garden and by the offering of garden produce at lunch. Finally, multi-factor analysis of variance (ANOVA) was performed on these data to determine if there was an effect between schools, and thus an effect due to treatment replications. 


\section{Chapter 4}

\section{RESULTS AND DISCUSSION}

\subsection{Demographic Characteristics of Sample}

The demographic characteristics of the sample groups were obtained from the schools' administrators. These data are reported in table 4.1. Demographic data about the entire sample group were obtained from the schools, in addition to the questionnaires, because the cafeteria observations did not collect demographic data about those participants who were present for the cafeteria observation. There was no significant difference between sample groups for the proportion of Hispanic participants, nor was there a difference between sample groups for the proportion of low-income participants. Low-income participants were defined as those who were eligible for free or reduced-cost lunch through NSLP during the study. 
Table 4.1. Demographic Characteristics of Sample Group.

\begin{tabular}{|l|l|l|l|}
\hline & Control Group & Treatment Group 1 & Treatment Group 2 \\
\hline School Name & $\begin{array}{l}\text { Maclary } \\
\text { Elementary School }\end{array}$ & $\begin{array}{l}\text { Marshall } \\
\text { Elementary School }\end{array}$ & $\begin{array}{l}\text { Keene Elementary } \\
\text { School }\end{array}$ \\
\hline $\mathrm{N}$ & 107 & 121 & 131 \\
\hline & & & $37.0 \%$ \\
\hline White & $73.1 \%^{*}$ & $41.0 \%$ & $47.2 \%$ \\
\hline Black & $14.2 \%^{*}$ & $40.8 \%$ & $4.4 \%$ \\
\hline Asian American & $3.9 \%$ & $10.3 \% *$ & $11.3 \%$ \\
\hline Hispanic & $8.5 \%$ & $7.6 \%$ & $38.2 \%$ \\
\hline & & & \\
\hline Low-income & $37.4 \%$ & $34.4 \%$ & \\
\hline
\end{tabular}

* Different from other sample groups at $p<0.05$

However, even though neither Hispanic ethnicity nor low-income status differed between the sample groups, the racial makeup of the groups differed significantly between the sample groups. The control group (participants from Maclary) differed from the other groups in having significantly $(p<0.05)$ more white participants and significantly $(p<0.05)$ fewer black participants. Treatment group 1 (participants from Marshall) had significantly $(p<0.05)$ more Asian-American participants.

\subsubsection{Questionnaire samples}

Questionnaires were distributed to the children. A total of 209 participants (58.2\%) responded to the pre-program questionnaires, while a total of 184 participants (51.2\%) responded to the post-program questionnaires. The low response rate was due to participant absence and difficulties in getting classroom teachers to allocate time for their students to take the questionnaires. A total of 14 parents of participants $(0.3 \%)$ withheld consent for their child to participate in the study, and thus 
did not answer the questionnaires. Questionnaires that were turned in blank, illegible, or with answers only to the three demographic questions (8 pre-program questionnaires and 5 post-program questionnaires) were excluded from the analysis. Demographic characteristics of the survey respondents are reported in Table 4.2.

Table 4.2. Demographic characteristics of survey respondents.

\begin{tabular}{|l|l|l|}
\hline & Pre-program & Post-program \\
\hline $\mathrm{N}$ & 209 & 184 \\
\hline Male & $51.0 \%$ & $50.4 \%$ \\
\hline White & $41.3 \%$ & $40.6 \%$ \\
\hline Black & $48.7 \%$ & $47.8 \%$ \\
\hline Asian-American & $4.4 \%$ & $4.9 \%$ \\
\hline Other race (write-in) & $5.6 \%$ & $6.6 \%$ \\
\hline Hispanic ethnicity & $19.9 \%$ & $18.2 \%$ \\
\hline
\end{tabular}

Write-in responses to the race question included Hispanic race (5.5\% in pre-program questionnaires and 6.5\% in post-program questionnaires) and mixed race (one response in both pre-program and post-program questionnaires). Hispanic ethnicity was reported by $19.9 \%$ of pre-program questionnaire respondents and by $18.2 \%$ of post-program questionnaire respondents. It is thought that the difference between the demographic data provided by the schools and the questionnaire data, especially with regard to Hispanic status, is due to the school classifying Hispanic as a racial category, and the questionnaire separating Hispanic ethnicity out into its own question.

\subsubsection{Observation sample}

In observation one (the pre-program observation), 286 participants (79.6\%) were observed in the cafeteria service line. In observation two (the post- 
program observation without school garden produce), 170 participants (47.3\%) were observed in the cafeteria service line. However, observation two was not performed at Keene because of issues surrounding the scheduling of an observation at the very end of the academic year. The observation was scheduled for the final day of lunch service, but the study participants at Keene (the fifth grade) did not eat lunch in the cafeteria, and observers were not notified that participants would not be eating lunch provided by the school that day. Out of the two experimental groups that did participate in observation two, $74.5 \%$ of participants were observed in the cafeteria service line. Finally, in observation three, 282 participants (78.6\%) were observed in the cafeteria service line.

Participants who were not observed either had parents who refused consent, were not present on the day when the observation was conducted, or brought lunch to school on the day that the observation was conducted. No demographic data were recorded about study participants who were observed in the cafeteria line.

\subsection{Research Questions}

This section provides answers to the seven research questions encompassed by this study presented in Section 2.2. Research questions 1, 2, 3, 6, and 7 were addressed by pre-program and post-program questionnaires. Research questions 4 and 5 were addressed by observations of participants in the cafeteria food service line.

\subsubsection{Research Question 1: How does participation in the EC school garden program influence participants' vegetable preferences?}

Questionnaire questions 5, 9, 10, and 11 addressed this research question. 


\subsubsection{Questionnaire Question 5}

Question 5 asked participants to circle the names of vegetables they enjoy eating from a list of common vegetables. Participants were also able to write in any other vegetables they enjoy eating. Participant responses to question 5 were composed together into a Like Score, as described in Section 3.4.1. The Like Score represents an estimate of the total number of vegetables that participants enjoy eating, out of a list of 23 common vegetables. Table 4.3 summarizes the responses to this question.

\subsection{Questionnaire Results}

The mean Like Score for all questionnaire respondents $(\mathrm{N}=209)$ was 8.77

\pm 4.30 vegetables in the pre-program questionnaire. The control group, Maclary, reported the lowest Like Score of $7.62 \pm 5.29$ vegetables. Marshall, the experimental group with one treatment replication, reported a pre-program Like Score of $8.89 \pm 4.19$ vegetables, whereas Keene, the experimental group with two treatment replications, reported the greatest pre-program Like Score of $9.13 \pm 4.03$ vegetables.

The mean Like Score for all respondents $(\mathrm{N}=182)$ from the post-program questionnaires was $9.04 \pm 4.62$ vegetables. Maclary reported the lowest post-program questionnaire Like Score of $7.46 \pm 5.16$ from $n=42$ responses. Marshall reported the highest post-program questionnaire Like Score of $9.62 \pm 4.27$ vegetables from $n=72$ responses, whereas Keene reported a post-program questionnaire Like Score of $9.40 \pm$ 4.56 vegetables from $n=68$ responses. 
Table 4.3. Estimate of the Number of Common Vegetables ${ }^{\mathrm{a}}$ Which School Children Enjoy Eating (Like Score) Before and After Participation a School Gardening Program.

\begin{tabular}{|l|l|l|l|}
\hline School (Replications) & Pre-Program & Post-Program & Difference \\
\hline Maclary (0) & $7.62 \pm 5.29$ & $7.46 \pm 5.16$ & $-0.16 \pm 1.18$ \\
\hline Marshall (1) & $8.89 \pm 4.19$ & $9.62 \pm 4.27$ & $0.73 \pm 0.69$ \\
\hline Keene (2) & $9.13 \pm 4.03$ & $9.40 \pm 4.56$ & $0.27 \pm 0.69$ \\
\hline
\end{tabular}

Mean \pm SD reported for pre- and post-program data. Mean \pm SEM reported for mean difference. No differences were significant at $p<0.05$.

a Out of a list of 23 common vegetables

\subsection{Discussion}

The Like Score difference between pre-program and post-program was $-0.16 \pm 1.18$ vegetables $(\mathrm{t}=-0.136$; d.f. $=75, p=0.89$, one-tailed $)$ for Maclary. The Like Score difference between pre-program and post-program was $0.73 \pm 0.69$ vegetables ( $\mathrm{t}=1.062$; d.f. $=148, p=0.29$, one-tailed) for Marshall, and the Like Score difference between pre-program and post-program was $0.27 \pm 0.69$ vegetables $(\mathrm{t}=$ 0.389 ; d.f. $=134, p=0.69$, one-tailed) for Keene. None of these differences were large enough to be statistically significant at the $p<0.05$ level.

At first, it may seem surprising that no treatment groups reported a significant increase in their Like Score. However, when considering that the garden vegetables had strong, bold, and often complex flavors (for example, radishes), it may be that several attempts at tasting may be needed before the children include those vegetables in the set of those they enjoy eating. This supposition is supported by research (25) that suggests 10-15 presentations of a food may be needed before a child included that food in his or her set of positive-preference foods. The data from this study only differentiate vegetables that the students enjoyed eating from those that they either had a neutral preference for or would seek to avoid eating. It, therefore, did not 
differentiate between neutral and negative preferences for individual vegetables, so further research would be necessary to determine whether students progressed towards a more positive preference for the individual vegetables tasted during the program.

\subsubsection{Questionnaire Question 9}

While question 5 asked participants about specific vegetables, questions 9, 10, and 11 asked participants about vegetables as a group. Question 9 asked participants how often they enjoy eating vegetables. Table 4.4 summarizes the responses to this question.

\subsection{Pre-program Questionnaire}

A total of 207 (57.7\%) participants responded to question 9 in the preprogram questionnaire. Maclary had the highest percentage of respondents reporting never enjoying eating vegetables (8.3\%), while Keene had the highest percentage of respondents reporting always enjoying eating vegetables (39.6\%). A total of 181 responses to question 9 were received. Maclary reported the highest percentage of respondents' never liking vegetables (7.1\%), while Keene reported the highest percentage of respondents’ always liking vegetables (46.3\%).

\subsection{Discussion}

None of the differences between pre-program and post-program questionnaires were significant. At Maclary, post-program responses showed a nonsignificant change from pre-program responses $\left(\chi^{2}=4.41\right.$; d.f. $\left.=3, p=0.22\right)$. At Marshall, post-program responses also showed a non-significant change from pre- 
Table 4.4. Frequency of Enjoying Eating Vegetables Before and After Participation in a School Garden Program

\begin{tabular}{|c|c|c|c|c|c|c|}
\hline & \multicolumn{2}{|c|}{ Maclary } & \multicolumn{2}{|c|}{ Marshall } & \multicolumn{2}{|c|}{ Keene } \\
\hline Response & Pre-program & Post-program & Pre-program & Post-program & Pre-program & Post-program \\
\hline $\mathrm{N}$ & 35 & 42 & 80 & 72 & 91 & 68 \\
\hline Never & $8.3 \%$ & $7.1 \%$ & $5.0 \%$ & $0 \%$ & $6.6 \%$ & $3.0 \%$ \\
\hline Occasionally & $33.3 \%$ & $14.3 \%$ & $6.3 \%$ & $5.6 \%$ & $6.6 \%$ & $6.0 \%$ \\
\hline Sometimes & $38.9 \%$ & $45.2 \%$ & $53.8 \%$ & $51.4 \%$ & $47.2 \%$ & $44.8 \%$ \\
\hline Always & $25.0 \%$ & $33.3 \%$ & $35 \%$ & $43.1 \%$ & $39.6 \%$ & $46.3 \%$ \\
\hline
\end{tabular}


program responses $\left(\chi^{2}=4.30\right.$; d.f. $\left.=3, p=0.23\right)$. At Keene, post-program responses also showed a non-significant change from pre-program responses $\left(\chi^{2}=1.47\right.$; d.f. $=3$, $p=0.68)$

While there was an increase from pre-program to post-program in each group, these increases were not large enough to be statistically significant. The data are inconclusive with respect to whether the EC program influences participants to consume vegetables more frequently.

\subsubsection{Questionnaire Question 10}

Question 10 asks participants how often they are likely to taste new vegetables when they are offered. Table 4.5 summarizes the data from this question.

\subsection{Questionnaire Results}

A total of 206 participants (57.4\%) responded to question 10 in the preprogram questionnaire. In the pre-program questionnaires, Keene reported the highest proportion of participants who would never try new vegetables (13.2\%), while Maclary reported the highest proportion of participants who would always try new vegetables (31.4\%). A total of 182 participants responded to question 10 in the postprogram questionnaire. In the post-program questionnaire, Marshall reported the highest proportion of participants who would never try new vegetables (9.7\%), while Maclary reported the highest proportion of participants who would always try new vegetables. 
Table 4.5. Frequency of Children's Trying New Vegetables If Offered Before and After Participation in a School Gardening Program.

\begin{tabular}{|c|c|c|c|c|c|c|}
\hline \multirow[b]{2}{*}{ Response } & \multicolumn{2}{|l|}{ Maclary } & \multicolumn{2}{|l|}{ Marshall } & \multicolumn{2}{|l|}{ Keene } \\
\hline & Pre-program & Post-program & Pre-program & $\begin{array}{l}\text { Post- } \\
\text { program** }\end{array}$ & Pre-program & $\begin{array}{l}\text { Post- } \\
\text { program*** }\end{array}$ \\
\hline $\mathrm{N}$ & 35 & 42 & 80 & 72 & 91 & 68 \\
\hline Never & $11.4 \%$ & $7.1 \%$ & $8.8 \%$ & $9.7 \%$ & $13.2 \%$ & $1.5 \%$ \\
\hline Occasionally & $22.9 \%$ & $14.3 \%$ & $36.2 \%$ & $12.5 \%$ & $30.8 \%$ & $17.6 \%$ \\
\hline Sometimes & $34.3 \%$ & $45.2 \%$ & $31.2 \%$ & $45.8 \%$ & $29.7 \%$ & $51.5 \%$ \\
\hline Always & $31.4 \%$ & $33.3 \%$ & $23.8 \%$ & $31.9 \%$ & $26.4 \%$ & $29.4 \%$ \\
\hline
\end{tabular}

** $\quad$ Different from pre-program at $p<0.01$

*** Different from pre-program at $p<0.001$ 


\subsection{Discussion}

At Maclary, there was no significant change between pre-program and post-program $\left(\chi^{2}=0.57\right.$; d.f. $\left.=3, p=0.90\right)$. The treatment groups, however, saw a significant increase between pre-program and post-program. Marshall reported a significant increase from pre-program to post-program with $p=0.01\left(\chi^{2}=11.62\right.$; d.f. $=$ $3)$, and Keene also saw increase with $p=0.003\left(\chi^{2}=14.07\right.$; d.f. $\left.=3\right)$.

At both of the schools that hosted the program, Keene and Marshall, participants reported a significant increase in their willingness to try new vegetables between the pre-program and post-program questionnaires. This suggests that participation in the program has increased participants’ openness to try new foods. Williams, et al. (26) suggests that children can develop trust when an adult presents foods that the children do not object to, leading to a lower inhibition to try new food. Consequently, a main benefit of the EC program seems to be that when participants taste new vegetables from the garden produce that they learn that tasting new vegetables is not a negative experience, and may be a neutral or even a positive experience. Thus, after participating in the program, participants may be more likely to taste new vegetables on their own.

\subsubsection{Questionnaire Question 11}

Question 11 asked participants if they would consider giving vegetables they think they do not like another try. Table 4.6 summarizes the data from this question. 
Table 4.6. Would Children Give Vegetables They Did Not Like Another Try After Participating in a School Garden Program?

\begin{tabular}{|c|c|c|c|c|c|c|}
\hline & \multicolumn{2}{|c|}{ Maclary } & \multicolumn{2}{|c|}{ Marshall } & \multicolumn{2}{|c|}{ Keene } \\
\hline Response & Pre-program & Post-program & Pre-program & Post-program & Pre-program & Post-program \\
\hline $\mathrm{N}$ & 35 & 40 & 79 & 72 & 91 & 68 \\
\hline Never & $20.0 \%$ & $17.5 \%$ & $13.9 \%$ & $5.6 \%$ & $27.5 \%$ & $23.5 \%$ \\
\hline Occasionally & $20.0 \%$ & $27.5 \%$ & $41.8 \%$ & $37.5 \%$ & $19.8 \%$ & $22.0 \%$ \\
\hline Sometimes & $31.4 \%$ & $32.5 \%$ & $26.6 \%$ & $34.7 \%$ & $37.4 \%$ & $33.8 \%$ \\
\hline Always & $28.6 \%$ & $22.5 \%$ & $17.7 \%$ & $22.2 \%$ & $15.4 \%$ & $20.6 \%$ \\
\hline
\end{tabular}

Differences between pre-program and post-program were not significant at $p<0.05$. 


\subsection{Questionnaire Results}

A total of 205 participants (57.1\%) responded to question 11 during the pre-program questionnaire. Keene reported the highest percentage of participants who would never give vegetables another try in both the pre-program (27.5\%) and postprogram (23.5\%) questionnaires. Maclary reported the highest percentage of participants who would always give vegetables they did not like another try in both the pre-program (28.6\%) and post-program (22.5\%) questionnaires.

\subsection{Discussion}

None of the differences between pre-program questionnaires and postprogram questionnaires were significant at $p<0.05$ for question 11. Data from Maclary failed to show a significant change with $\mathrm{p}=0.85\left(\chi^{2}=0.77\right.$; d.f. $\left.=3\right)$. Data from Marshall also failed to show a significant change with $\mathrm{p}=0.26\left(\chi^{2}=4.03\right.$; d.f. $=$

3). Data from Keene also failed to show a significant change with $p=0.78\left(\chi^{2}=1.07\right.$; d.f. = 3).

The questionnaire responses did not differ significantly between preprogram and post-program. The data were thus inconclusive as to whether EC program participants were willing to give vegetables they did not like another try.

\subsubsection{Conclusions for Research Question 1}

Research question 1 asked whether participation in the EC program influenced participants' vegetable preferences. It has been shown that students who participated in the EC program showed an increase in their willingness to try new vegetables. However, data from other questions were inconclusive. 
It may be that one of the main benefits to the EC program is that it helps program participants develop a more open mind to novel foods. It is important for children to taste new foods because being introduced to a food reduces a significant barrier to incorporating those foods into the diet. As the research (26) shows, children who are introduced to a food in an environment that they trust are more likely to have a positive reaction to that food. This research thus supports the results obtained by Williams, et al. (26).

\subsubsection{Research Question 2: Did students in the EC program taste new vegetables that they had not previously eaten?}

Questionnaire question 4 addresses this research question. Question 4 asked participants to circle the names of vegetables they had previously tasted from a list of common vegetables. Participants were also able to write in any other vegetables they had previously tasted. Participant responses to question 4 were composed together into a Taste Score, as described in Section 3.4.1. The Taste Score represents an estimate of the total number of vegetables that participants had previously tasted, out of a list of 23 common vegetables. Table 4.7 summarizes the responses to this question.

Only responses from Keene showed a significant change from preprogram to post-program in the Taste Scores. At Maclary, there was a mean decrease of 0.22 vegetables which was not significant at $p<0.05$ ( $\mathrm{t}=-0.189$; d.f. $=77$, onetailed). Similarly, at Marshall, a mean increase of 0.89 vegetables was not significant at $p<0.05(\mathrm{t}=1.39$; d.f. $=150$, one-tailed). However, at Keene, there was a mean increase of 1.14 vegetables, which was significant at $\mathrm{p}=0.05(\mathrm{t}=1.694$; d.f. $=123$, one-tailed). 
Table 4.7. Estimate of the Number of Common Vegetables ${ }^{\mathrm{a}}$ That School Children Have Tasted (Taste Score) Before and After Participation a School Gardening Program.

\begin{tabular}{|l|l|l|l|}
\hline School (Replications) & Pre-Program & Post-Program & Difference \\
\hline Maclary (0) & $12.68 \pm 5.01$ & $12.46 \pm 5.34$ & $-0.22 \pm 1.17$ \\
\hline Marshall (1) & $13.64 \pm 4.11$ & $14.53 \pm 3.77$ & $0.89 \pm 0.64$ \\
\hline Keene (2) & $14.19 \pm 3.61$ & $15.33 \pm 4.60$ & $1.14 \pm 0.67 *$ \\
\hline
\end{tabular}

Mean \pm SD reported for Pre-program, post-program results. Mean \pm SEM reported for mean difference.

* $\quad$ Difference significant at $p=0.05$.

a From a list of 23 common vegetables

Keene, which has hosted a garden for 2 academic years, had a larger change than at Marshall, which has only hosted a garden for less than 1 academic year. It may be that the students at Marshall were still somewhat inhibited in trusting the tasting of garden produce, as the garden was still new to them. However, students at Keene, having seen in the previous academic year that there had been no negative consequences to peers from sampling the garden produce could trust that tasting the garden produce would not cause them harm. Thus, it is unsurprising that Keene was the only sample group to report a significant increase in their Taste Score.

\subsubsection{Research Question 3: How does participation in the EC garden program influence participants' consumption of the vegetable offering at School Lunch?}

This research question is addressed by questionnaire question 6, which asked participants how many times per week they consume the vegetable offering at school lunch. Responses to this question are summarized in Table 4.8. 
Table 4.8 Number of Times per Week School Children Consume Vegetables at School Lunch Before and After Participation in a School Garden Program

\begin{tabular}{|l|l|l|l|}
\hline School (Replications) & Pre-Program & Post-Program & Difference \\
\hline Maclary (0) & $1.84 \pm 1.06$ & $1.93 \pm 1.32$ & $0.09 \pm 0.27$ \\
\hline Marshall (1) & $2.08 \pm 1.45$ & $2.17 \pm 1.36$ & $0.09 \pm 0.23$ \\
\hline Keene (2) & $1.87 \pm 1.34$ & $2.22 \pm 1.67$ & $0.35 \pm 0.25$ \\
\hline
\end{tabular}

Mean \pm SD reported for pre- and post-program data. Mean \pm SEM reported for mean difference. No differences were significant at $p<0.05$.

No differences between pre-program questionnaires and post-program questionnaires existed. At Maclary, the mean difference of 0.09 times per week between pre-program and post program was not significant at $p<0.05$ ( $\mathrm{t}=0.336$; d.f. = 76, one-tailed). At Marshall, the mean difference of 0.09 times per week was also not significant at $p<0.05$ ( $\mathrm{t}=0.395$; d.f. $=150$, one-tailed $)$. At Keene, the mean difference of 0.35 times per week was also not significant at $p<0.05(\mathrm{t}=1.423$; d.f. $=$ 125, one-tailed), although it approached significance at $p=0.08$.

While there were no significant differences in any of the treatment groups, the difference at Keene was close to significance. A topic for future research may be to investigate this question further, to see if the results obtained at Keene suggest a real effect of children's consumption habits moving in the right direction, or if they are just due to chance.

\subsubsection{Research Question 4: Does the fact that the vegetable offered at school lunch is grown in the school garden by students and their peers influence students' choice to consume or not consume the vegetable?}

This research question is addressed by the cafeteria observations.

Cafeteria observation data are summarized in Table 4.9. Recall that observation one 
was the pre-program observation, observation two was the post-program observation without using garden produce in the cafeteria, and observation three was the postprogram observation using produce grown in the cafeteria in the two treatment groups to be exposed to the program.

\subsubsection{Observation One}

At observation one, 68 participants (63.5\%) purchased (or received free) school lunch at Maclary. Of those 68, a total of 15 participants (22\%) chose to take a salad from the lunch line. The salad that was available was a 5-ounce plastic cup filled with iceberg lettuce and shredded carrots. Those who purchased a salad were able to receive 1 packet of dressing of their choice of flavor to accompany their salad.

Observation one at Marshall saw 92 participants (76\%) purchase or receive school lunch. Of those 92, a total of 16 participants (17.4\%) chose to take a salad from the lunch line. The salad that was available was a 5-ounce Styrofoam cup filled with spinach. The salad did not contain any other ingredients, but those who purchased a salad were still able to receive 1 packet of dressing.

Observation one at Keene saw 126 participants (96.2\%) purchase or receive school lunch. Of those 126, a total of 28 participants (22.2\%) chose to take a salad from the lunch line. The salad that was available at Keene was similar to the salad available at Maclary; it included shredded carrots in addition to the iceberg lettuce.

\subsubsection{Observation Two}

Observation two at Maclary saw 74 participants (69.2\%) purchase or receive school lunch. Of those 74 , a total of 15 participants (20.3\%) chose to take a 
salad from the lunch line. The salad that was available was similar to the salad available during observation one.

Table 4.9. Observation of School Lunch to Determine If Using School Garden Produce in School Lunch Has an Effect Upon Children's Food Choices

\begin{tabular}{|c|c|c|c|}
\hline $\begin{array}{l}\text { Observation } \\
\text { Number }\end{array}$ & School & $\mathrm{N}$ & $\begin{array}{l}\text { Participants That } \\
\text { Chose Salad }\end{array}$ \\
\hline \multirow[t]{3}{*}{1} & Maclary & 68 & $22.1 \%$ \\
\hline & Marshall & 92 & $17.4 \%$ \\
\hline & Keene & 126 & $22.2 \%$ \\
\hline \multirow[t]{3}{*}{2} & Maclary & 74 & $20.3 \%$ \\
\hline & Marshall & 96 & $24.0 \%$ \\
\hline & Keene & -- & -- \\
\hline \multirow[t]{3}{*}{3} & Maclary & 76 & $25.0 \%$ \\
\hline & Marshall & 95 & $28.4 \% *$ \\
\hline & Keene & 111 & $61.3 \% * * *$ \\
\hline
\end{tabular}

Observation two at Marshall saw 96 participants (79.3\%) purchase or receive school lunch from the cafeteria. Of those 96, a total of 23 participants (24\%) chose to take a salad as a part of their meal. The salads that were offered were similar to those offered during observation one at Marshall.

Observation two was not performed at Keene, as described in Section 4.1.2. The day that this observation was scheduled to be performed at Keene was the last day of food service at the school before summer break, but the observers did not 
know the fifth grade (the study sample) would not be present during the lunch service that day.

\subsubsection{Observation Three}

Observation three at Maclary saw 76 participants (71\%) purchase or receive school lunch. Of those 76 , a total of 19 (25\%) chose to take a salad. The salad offered was similar to that offered in both other observations at Maclary.

Observation three at Marshall saw 95 participants (78.5\%) purchase or receive school lunch. Of those 95, a total of 27 (28.4\%) chose to take a salad. The salad offered was a 5-ounce Styrofoam cup filled with spinach from the school garden, with no additional ingredients. Although Marshall was the only school to use spinach instead of lettuce as its main salad ingredient, the use of spinach was consistent across all observations at Marshall. There was a small sign on letter-size paper advertizing the garden produce salads, but the food service staff did not encourage the children to try the salad.

Observation three at Keene saw 111 participants (84.7\%) purchase or receive school lunch. Of those 111 , a total of 68 participants (61.3\%) chose to take a salad. The salad available at observation three at Keene contained lettuce and sliced radishes from the garden. However, the radish slices were hidden at the bottom of the cup, so participants in the line did not know about the radishes in the salad. There was a small sign on letter-size paper at Keene also advertizing the garden produce salads. However, unlike at Marshall, the cafeteria staff encouraged the children to try the salad.

At observation three at both Marshall and Keene, there were some interesting and unexpected observations of peer effects in the participants’ lunch 
decisions. Groups of three or four participants would see the signs and discuss the salads within the group. Then, each member of the group would take a salad. Also, sometimes one participant would encourage others in line near him or her to try the salad.

\subsubsection{Discussion}

At Maclary, there was no significant change in the proportion of participants who chose a vegetable between observations one and two ( $\mathrm{z}=0.261$; onetailed, $p=0.26)$, observations one and three $(\mathrm{z}=0.416$; one-tailed, $p=0.42)$, and observations two and three $(\mathrm{z}=0.694$; one-tailed, $p=0.69)$. Marshall showed an increase of $11 \%$ of participants between observations one and three, with $\mathrm{p}=0.04$ (z $=$ 1.813; one-tailed); however, it did not show a significant increase between observations one and two $(\mathrm{z}=1.117$; one-tailed, $p=0.13)$ nor between observations two and three $(\mathrm{z}=0.702$; one-tailed, $p=0.24)$. Keene showed an increase of $39 \%$ of participants between Observations one and three, with $p<0.0001$ ( $\mathrm{z}=6.59$; onetailed).

The cafeteria observations showed a significant increase in participants’ choosing a salad between observations one and three at both experimental group schools. Unfortunately, the data point for observation three at Keene may be invalid, since the cafeteria staff was more vocal about promoting the garden produce salad than they were about promoting the regular mixed salad from observation one. Observation three at Keene is, however, helpful in understanding that extra salesmanship for the healthier choices by the cafeteria staff may lead to students making healthier food choices. Thus, it would be beneficial for school gardening programs looking to use the 
garden as a tool to change students' eating habits to secure the support of school staff, including the cafeteria workers.

However, at Marshall, cafeteria staff did not differentially promote the garden produce salad. At Marshall, there was a smaller, but still significant difference between observations one and three, and so, it is possible to conclude that the EC program and the offering of garden produce at lunch together caused an increase in students' choosing to take a vegetable at school lunch. There was no statistically significant difference between observations one and two, and between observations two and three, though, so the data cannot tell us whether it was the program or the offering garden produce at lunch that provided more of an impact on students' food choices.

\subsubsection{Research Question 5: What importance does repeated exposure of the students to EC garden program have upon students' consumption of vegetables at School Lunch?}

Research question 5 was addressed by the cafeteria observations. Data from the cafeteria observations are summarized in Table 4.7. Results from the cafeteria observations are reported in Sections 4.2.4.1, 4.2.4.2, and 4.2.4.3.

Analysis of variance (ANOVA) was performed on the observation data to determine if the number of treatment replications had a significant effect upon whether participants who had participated in the program multiple times had a greater likelihood of choosing the vegetable. The analysis of variance results were inconclusive in showing whether repeated exposure to the program affected participants' choices ( $\mathrm{F}=3.04$; d.f. $=5,2, p=0.27$ ).

Because the results of the ANOVA were inconclusive, it is not possible to draw a conclusion about whether repeated exposure to the EC program has an effect 
on students' choices at school lunch. Further research should include more treatment replications to determine if repeated exposure does have an effect.

\subsubsection{Research Question 6: Do children's gender, race, and Hispanic status have an effect on their preferences for vegetables?}

This question is addressed by examining the questionnaire data for differences in responses between participants’ gender, race, and Hispanic status. Because pre-program and post-program questionnaires were administered to the same sample groups, this analysis examines only one set of questionnaires. Post-program questionnaires were chosen by coin flip to be examined.

\subsubsection{Gender}

There was a significant difference between males' and females' responses when asked if they were more likely to eat a vegetable at lunch if the vegetable came from the school garden. The gender data are summarized in Table 4.10. A chi-square analysis of these data showed a significant difference between genders for responses to this question $\left(\chi^{2}=14.57\right.$; d.f. $\left.=2, p=0.0007\right)$.

Table 4.10. Gender Differences Between Children When Asked If They Would Be More Likely to Eat a Vegetable At School Lunch When It Was Grown in the School Garden

\begin{tabular}{|l|l|l|}
\hline & Males & Females \\
\hline & & \\
\hline $\mathrm{N}$ & 92 & 90 \\
\hline Less Likely & $8.8 \%$ & $38.2 \%$ \\
\hline About the Same & $44.1 \%$ & $50.0 \%$ \\
\hline More Likely & $47.1 \%$ & $11.8 \%$ \\
\hline
\end{tabular}

Males and females significantly different at $p=0.0007\left(\chi^{2}=14.57\right.$; d.f. $\left.=2\right)$. 
This observed difference between males and females was unexpected. The data were not helpful on why this might be the case; no other difference in questionnaire responses could be found for males and females. Consequently, examining why male students might have a different preference than female students for eating garden produce at school lunch may make for an interesting research opportunity.

No other significant differences were found between males and females in responses to the other questions:

1. Taste Score $(\mathrm{t}=1.55$; d.f. $=180$, two-tailed, $p=0.12)$,

2. $\quad$ Like Score $(\mathrm{t}=1.593$; d.f. $=180$, two-tailed, $p=0.11)$,

3. number of times per week that participants eat vegetables at school lunch $(\mathrm{t}=1.529$; d.f. $=180$, two-tailed, $p=0.12)$,

4. $\quad$ gardening outside $\operatorname{school}\left(\chi^{2}=2.07\right.$; d.f. $\left.=1, p=0.15\right)$,

5. $\quad$ enjoying vegetables $\left(\chi^{2}=3\right.$; d.f. $\left.=3, p=0.39\right)$,

6. willingness to try new vegetables $\left(\chi^{2}=6.75\right.$; d.f. $\left.=3, p=0.08\right)$, and

7. willingness to give vegetables they did not like another try $\left(\chi^{2}=\right.$ 4.15; d.f. $=3, p=0.25$ ).

\subsubsection{Race}

There was a significant difference between races for responses to the question of whether participants garden outside of school. White participants $(n=74)$ reported 78.3\% of participants gardening outside of school; black participants $(n=86)$ reported 39.5\% of participants gardening outside of school; Asian-American participants $(\mathrm{n}=9)$ reported $77.8 \%$ of participants gardening outside of school; 
participants who wrote-in Hispanic as a response to the race question $(n=12)$ reported 75\% of participants gardening outside of school; and the participant who wrote-in mixed as a response to the race question reported gardening outside of school. A chisquare analysis of these data showed a significant difference between races $\left(\chi^{2}=\right.$ 30.04; d.f. $=4, p<0.0001)$. Further research should look at why this is the case. Is the difference seen between white participants and black participants due to socioeconomic factors or to cultural factors?

No other significant differences were found between races in responses to the other questions:

1. Taste Score $(\mathrm{F}=1.63$; d.f. $=4,177, p=0.20)$,

2. Like Score $(\mathrm{F}=0.78$; d.f. $=4,177, p=0.54)$,

3. number of times per week that participants eat vegetables at school lunch $(\mathrm{F}=1.59$; d.f. $=4,177, p=0.17)$,

4. whether participants would be more likely to consume vegetables at lunch if those vegetables came from the school garden $\left(\chi^{2}=10.85\right.$; d.f. $\left.=8, p=0.21\right)$,

5. enjoying vegetables $\left(\chi^{2}=14.89\right.$; d.f. $\left.=12, p=0.25\right)$,

6. willingness to try new vegetables $\left(\chi^{2}=18.92\right.$; d.f. $=12, p=$ 0.09), and

7. willingness to give vegetables that they do not like another try $\left(\chi^{2}=17.3\right.$; d.f. $\left.=12, p=0.14\right)$.

\subsubsection{Hispanic Ethnicity}

Responses of participants with Hispanic ethnicity $(\mathrm{n}=33)$ were not significantly different from those without Hispanic ethnicity $(n=149)$. This result was surprising because it was assumed in picking the sample groups that Hispanic 
participants would be exposed to a different set of vegetables outside of the school environment, which may have affected their preferences for and consumption of vegetables. This non-significant difference between Hispanic participants and nonHispanic participants was true for every question, including:

1. Taste Score $(\mathrm{t}=-1.15$, d.f. $=180$, two-tailed, $p=0.25)$,

2. Like Score $(\mathrm{t}=0.53$, d.f. $=180$, two-tailed, $p=0.60)$,

3. number of times per week that participants ate a vegetable at school lunch $(\mathrm{t}=0.34$, d.f. $=180$, two-tailed, $p=0.73)$,

4. whether participants would be more likely to consume vegetables at lunch if those vegetables came from the school garden $\left(\chi^{2}=0.79\right.$; d.f. $\left.=2, p=0.68\right)$,

5. whether participants garden outside of school $\left(\chi^{2}=0.64\right.$; d.f. $=$ $1, p=0.42)$,

6. enjoying vegetables $\left(\chi^{2}=8.50\right.$; d.f. $\left.=4, p=0.07\right)$,

7. willingness to try new vegetables $\left(\chi^{2}=1.80\right.$; d.f. $\left.=3, p=0.61\right)$, and

8. willingness to give vegetables that they do not like another try $\left(\chi^{2}=0.38\right.$; d.f. $\left.=3, p=0.94\right)$.

\subsubsection{Research Question 7: How does gardening experience outside the EC program affect children's preferences for vegetables and willingness to try new vegetables?}

Research question 7 was addressed by examining the questionnaire questions against participants’ responses to questionnaire question 8.

Those participants who gardened outside of school reported that they consumed vegetables at school lunch a significantly larger number of times than those who did not garden outside school. While participants who did not garden outside 
school $(n=75)$ only consumed vegetables at school lunch $1.61 \pm 1.50$ times per week, participants who did garden outside school consumed vegetables at school lunch 2.65 \pm 1.67 times per week. The difference between these two groups, $1.04 \pm 0.40$ times per week, was significant at $p=0.009(\mathrm{t}=2.639$; d.f. $=180$, two-tailed $)$. This significant difference in vegetable consumption agrees with research conducted by Alaimo, et al. (18) who reported that gardeners self-report that they consume more vegetables than non-gardeners.

Furthermore, those participants who garden outside of school were also more willing than the other participants to give another chance to vegetables they did not like tasting the first time. This was significant at $p<0.0001\left(\chi^{2}=22.63\right.$; d.f. $\left.=3\right)$. This result suggests that children who do garden keep a more open mind to trying new foods, especially new vegetables. This would be a nutritional benefit to these children, since it promotes increased dietary variety.

No other significant differences were found between participants who garden outside of school and those who do not in responses to the other questions:

1. Taste Score $(\mathrm{t}=1.754$; d.f. $=180$, two-tailed, $p=0.08)$,

2. Like Score $(\mathrm{t}=1.75$; d.f. $=180$, two-tailed, $p=0.08)$,

3. whether participants would be more likely to consume vegetables at lunch if those vegetables came from the school garden $\left(\chi^{2}=3.86\right.$; d.f. $\left.=2, p=0.14\right)$,

4. enjoying vegetables $\left(\chi^{2}=7.79\right.$; d.f. $\left.=3, p=0.051\right)$, and

5. willingness to try new vegetables $\left(\chi^{2}=6.41\right.$; d.f. $\left.=3, p=0.09\right)$. 


\subsection{Limitations and Recommendations for Future Research}

\subsubsection{Threats to Internal Validity}

There was a possibility of a threat to the internal validity of the study due to selection bias at the post-program questionnaires and observations. Because these data collection opportunities happened near or after Memorial Day, there were fewer participants in attendance for those days, due to absences for family vacations. This research, therefore, assumes that the participants absent on those days were similar in achievement and attitude toward school as those who were present. If the absent participants were dissimilar, then their attitudes toward the school gardening program may be different, and, thus, they would be less likely to choose the garden produce salad or respond with favorable vegetable preferences in the surveys.

Another possible selection bias was present in the assumption that students who bring lunch to school are similar to those who purchase lunch at school or who receive free lunch through NSLP. It may be that parents who pack lunch for the students may not trust the nutritional quality of the food served at school lunch. However, it may be reasonable to assume that the students' bringing lunch to school was unchanged by the EC program, so the change between pre-program and postprogram should not be affected. It may be an interesting research opportunity to evaluate whether students who purchase (or receive free) lunch at school have different food consumption habits at home than do students who bring lunch to school.

There was a limitation to the construct validity of the classroom observations. In this study, only the taking of a salad in the lunch line was recorded; no data were collected about whether students ate those salads or not. This study assumed that the amount of salad actually consumed was similar to that reported by 
the School Nutrition Dietary Assessment Study (15). Further research should include a plate waste study to determine whether participants actually ate what they purchased from the lunch line.

There may also be a testing threat to internal validity. The combination of the questions asked on the questionnaires and the presence of observers in the lunch line may have affected the participants' answers on the questionnaires and their choices in the lunch line. During the cafeteria observations, several participants correctly guessed what the observers were looking for and then chose a salad. It is unknown whether those participants changed their behavior as a result of the observer's presence. It is also unknown whether the observer's presence affected other participants’ choices.

Finally, the novelty effect was not controlled for in this study. It may be that more participants took a garden produce salad simply because it was something new, and they wanted to try it out. Further research should perform several observations with the garden produce to determine if it truly increases participants' food choices over the long-term, or if participants' food choices regress back to where they were before the program because the novelty of eating produce grown in the school garden has worn off.

\subsubsection{Threats to External Validity}

There is a threat to the external validity of this study due to its having selected a convenience sample in a middle-class suburban area of New Castle County, Delaware. These data may not have relevance in areas with demographics different from the study’s sample, such as inner-city environments, rural environments, or areas with a large recent immigrant population. 
The data from this study are also not generalizable to children of other age groups, such as middle school and high school students. In general, children become less likely to try new foods as they age (26). Thus, there may be different effects for older children. Further research should be done to determine what effects school gardens have on high school students. Fortunately, there are several high school garden programs around the United States that have not yet been evaluated for their effectiveness.

\subsubsection{Other Limitations}

One final limitation to the study is that it assumes that changes in participants' attitudes and behaviors towards vegetables would change during the short time frame of the program, which lasted about 2 months. It is entirely possible that the program had effects upon participants that do not manifest until participants have had time to reflect upon what they have learned. Future research into the effectiveness of school garden programs should follow-up on participants a year or two after having participated in school garden programs to determine if any other effects appear.

\subsubsection{Conclusions on Limitations}

Many of the limitations of this study stem from the difficulties in working with populations, especially with schools and their staffs who never seem to have enough time to complete all the requirements mandated upon them, let alone accommodate a research project. An example of these difficulties would be getting the questionnaires completed. School administrators only allowed questionnaire administration after standardized testing ended in March. However, that only left 2 weeks before the school gardens began operation for the spring. Because some 
classroom teachers were not cooperative, not all classes completed the questionnaires before gardening began, and so some classes failed to complete the questionnaires. Furthermore, the cafeteria staff at Keene had a much more positive attitude toward the garden produce than did the cafeteria staff at Marshall. This is likely due to the garden having been established the previous year at Keene, and that staff have come to see the school garden as an ongoing project that is part of the school community. 


\section{Chapter 5}

\section{CONCLUSION}

School lunch presents a useful opportunity to increase children’s vegetable consumption. Research into the National School Lunch Program (NSLP) shows that students eat over 35\% of their daily food intake, as measured by energy content, at school (15). However, only 31.6\% of students consume a vegetable in NSLP schools (16). Encouraging vegetable consumption at school lunch presents a way to increase children's overall vegetable consumption. Using school garden produce in the school lunch program has been an understudied approach to attempt to increase children’s vegetable consumption during school hours.

Following the example of California, school gardens have seen a resurgence over the past 10 years as a way to extend the educational environment of the school. School gardens have long been associated with science education, but educators are now starting to realize their potential for nutrition education as well, specifically as a way to demystify unfamiliar vegetables, so that students would be more apt to incorporate those vegetables into their food preferences.

In this study, fourth and fifth graders at three schools in Christina School District, Delaware, were studied to determine what impact the school garden has upon students' vegetable preferences and students' food choices at school lunch. This study found that participation in the EC program increased participants' willingness to try new vegetables by providing participants with neutral or even positive experiences 
tasting new vegetables, so that they learn to trust that new vegetables that they taste will not harm them.

Although this study did not find that participation in the EC program increased the amount of vegetables the participants consumed at school lunch, it did find that using school garden produce as a hook to get children who have worked in the garden to consume that produce at school lunch is a successful tactic to promote vegetable consumption. However, it is likely that participation in the school gardening program and using school garden produce in the cafeteria together create the increase in vegetable consumption seen in observation three.

Also, the study did not find a statistically significant increase in vegetable consumption at school lunch from a second exposure to the program; however, it did find a small increase that approached significance. It may be that repeated exposures to the program provide diminishing returns, so further research should include more program exposures to determine if and when the trend of increasing vegetable consumption levels off. This will allow school garden programs to determine where to best devote their resources to promote children's vegetable consumption, whether it be to provide another program exposure to previous participants or to begin to educate a new set of children.

Interestingly, the study found that male participants claimed to be more likely than their female counterparts to try school garden produce in the cafeteria. However, the cafeteria observations did not break down the participants by gender, so it is unknown whether the males followed through on their claim to try the garden produce. 
This study also found that white children were more likely than black children to garden outside school. Gardening outside school was itself correlated with two other variables: consuming vegetables at school lunch more frequently and being willing to give vegetables they did not like another chance. However, these two variables were not correlated with race, even though gardening outside school was correlated with race.

While there are limitations to the validity of this study, it shows that using school garden produce may help schools encourage the students' consumption of vegetables during the school day. Further research is needed to determine what effect advertizing the garden produce and getting the cafeteria staff to promote choosing the garden produce has upon students' food choices. Also, longitudinal studies, examining a group of students who participate in a school gardening program throughout their elementary school career, would be helpful in determining the longterm effects of using school gardens to influence students' food habits and choices. 


\section{REFERENCES}

1. Centers for Disease Control and Prevention. Obesity and overweight: childhood overweight and obesity. Updated: 25 November 2008.

http://www.cdc.gov/nccdphp/dnpa/obesity/childhood/index.htm. Accessed: 27 December 2008.

2. Ogden CL, Carroll MD, Flegal KM. High body mass index for age among US children and adolescents, 2003-2006. JAMA. 2008;299:2401-2405.

3. Freedman DS, Mei Z, Srinivasan SR, Berenson GS, Dietz WH.

Cardiovascular risk factors and excess adiposity among overweight children and adolescents: the Bogalusa Heart Study. J Pediatr. 2007;150:12-17.

4. $\quad$ Rodriguez MA, Winkleby MA, Ahn D, Sundquist J, Kraemer HC. Identification of population subgroups of children and adolescents with high asthma prevalence: findings from the Third National Health and Nutrition Examination Survey. Arch Pediatr Adolesc Med. 2002;156:269-275.

5. Mallory GB, Fiser DH, Jackson R. Sleep-associated breathing disorders in morbidly obese children and adolescents. J Pediatr. 1989;115:892-897.

6. Must A, Anderson SE. Effects of obesity on morbidity in children and adolescents. Nutr Clin Care. 2003;6;4-11.

7. United States Department of Health and Human Services. Healthy People 2010: Understanding and Improving Health. 2nd ed. Washington, D.C.: U.S. Government Printing Office; 2000.

8. United States Department of Health and Human Services. Chapter 19: overweight and obesity. In: Healthy People 2010 Midcourse Report. Washington, D.C.: U.S. Government Printing Office; 2006. 
9. Centers for Disease Control and Prevention. Obesity and overweight: childhood overweight: contributing factors. Updated: November 25, 2008. http://www.cdc.gov/nccdphp/dnpa/obesity/childhood/contributing_factors.htm . Accessed: December 27, 2008.

10. Produce for a Better Health Foundation. State of the plate 2005: Study on America's consumption of fruits and vegetables. http://www.pbhfoundation.org/pdfs/pulse/research/pbhresearch/stateoftheplate /2005_state_of_the_plate.pdf. Accessed: October 5, 2009.

11. United States Department of Health and Human Services. Dietary Guidelines for Americans 2005. Washington, D.C.: Government Printing Office; 2005.

12. Condon EM, Crepinsek MK, Fox MK. School meals: types of foods offered to and consumed by children at lunch and breakfast. J Am Diet Assoc. 2009;109:S67-S68.

13. Howerton MW, Bell BS, Dodd KW, Berrigan D, Stolzenburg-Solomon R, Nebeling L. School-based nutrition programs produced a moderate increase in fruit and vegetable consumption: meta and pooling analysis from 7 studies. $J$ Nutr Educ Behav. 2007;39:186-196.

14. Perez-Rodrigo C, Klepp K-I, Yngve A, Sjöström M, Stockley L, Aranceta J. The school setting: an opportunity for the implementation of dietary guidelines. Public Health Nutr. 2001;4:717-724.

15. Briefel RR, Wilson A, Gleason PM. Consumption of low-nutrient, energydense foods and beverages at school, home, and other locations among school lunch participants and nonparticipants. J Am Diet Assoc. 2009;109:S20-S30.

16. Briefel RR, Crepinsek MK, Cabili C, Wilson A, Gleason PM. School food environments and practices affect dietary behaviors of US public school children. J Am Diet Assoc. 2009;109:S91-S107.

17. Graham H, Beall DL, Lussier M, McLaughlin P, Zidenberg-Cherr S. Use of school gardens in academic instruction. J Nutr Educ Behav. 2005;37:147-151.

18. Alaimo K, Packnett E, Miles RA, Kruger DJ. Fruit and vegetable intake among urban community gardeners. J Nutr Educ Behav. 2008;40:94-101.

19. Morris JL, Neustadter A, Zidenberg-Cherr S. First-grade gardeners more likely to taste vegetables. California Agriculture. 2001;55:43-46. 
20. McAleese JD, Rankin LL. Garden-based nutrition education affects Fruit and vegetable consumption in sixth-grade adolescents. J Am Diet Assoc. 2007;107:662-665.

21. Houlihan B, Green M. The changing status of school sport and physical education: explaining policy change. Sport, Education, and Society. 2006;11:73-92.

22. Parmer SM, Salisbury-Glennon J, Shannon D, Struempler B. School gardens: an experiential learning approach for a nutrition education program to increase fruit and vegetable knowledge, preference, and consumption among secondgrade students. J Nutr Educ Behav. 2009;41:212-217.

23. Position of the American Dietetic Association, Society for Nutrition Education, and American School Food Service Association: nutrition service: an essential component of comprehensive school health programs. J Nutr Educ Behav. 2003;35:57-67.

24. Robinson-O’Brien R, Story M, Heim S. Impact of garden-based youth nutrition intervention programs: a review. J Amer Diet Assoc. 2009;109:273280.

25. Pliner P, Pelchat M, Grabski M. Reduction of neophobia in humans by exposure to novel foods. Appetite. 1993;20:111-121.

26. Williams KE, Paul C, Pizzo B, Riegel K. Practice does make perfect. A longitudinal look at repeated taste exposure. Appetite. 2008;51:739-742. 


\section{Appendix A}

\section{HUMAN SUBJECTS BOARD REVIEW}

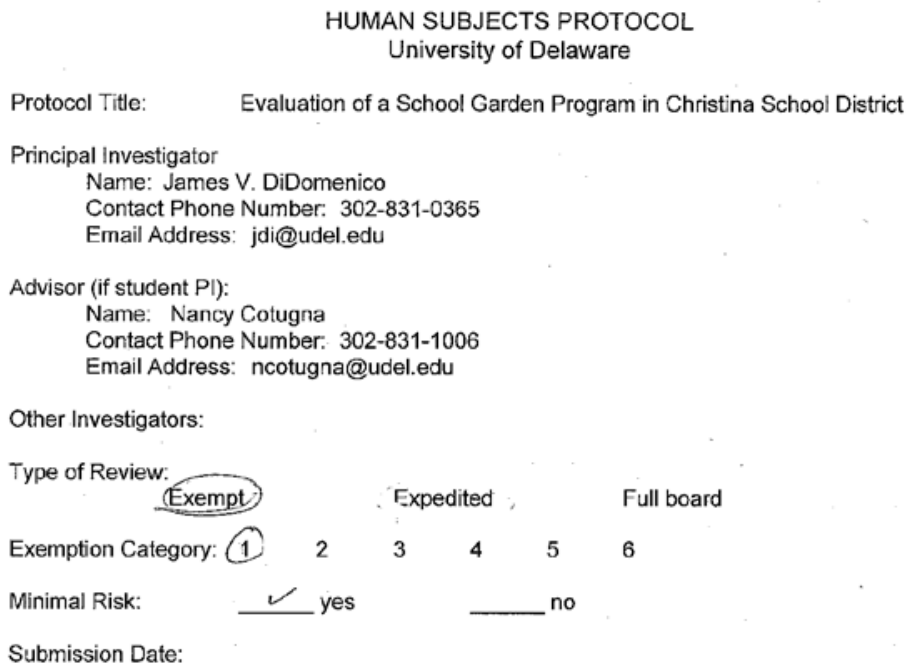

\begin{tabular}{|c|c|}
\hline $\begin{array}{l}\text { HSRB Approval Signature } \\
\text { Eyenabeth Desfies Ploso }\end{array}$ & $\begin{array}{l}\text { Approval Date } \\
2 / 25 / 09\end{array}$ \\
\hline $\begin{array}{l}\text { HS Number } \\
\qquad x \operatorname{mp} 375\end{array}$ & $\begin{array}{l}\text { Approval Next Expires } \\
n / a\end{array}$ \\
\hline
\end{tabular}

Investigator Assurance:

By submitting this protocol, I acknowledge that this project will be conducted in strict accordance with the procedures described. I will not make any modifications to this protocol without prior approval by the HSRB. Should any unanticipated problems involving risk to subjects, including breaches of guaranteed confidentiality occur during this project, I will report such events to the Chair, Human Subjects Review Board immediately.

Signature of Investigator:

Date: 


\section{Parental Permission for Child's Participation in Gardening Education Evaluation}

Dear parent,

Your child, as a $4^{\text {th }}\left(5^{\text {th }}\right)$ grade student at __ Elementary School, will participate (has been participating) in the Christina School District's Education Cultivation garden education . program. I am asking your permission for your child to participate in the evaluation component of the program as a part of my Master's degree research at the University of Delaware. Your child will be asked to do the following in the classroom:

- Complete two short anonymous surveys about which vegetables he or she enjoys eating, and whether he or she participates in gardening activities outside the school. In addition, students will be asked to check off their race, ethnicity, and gender for statistical purposes. They cannot be identified by this information. Each form is expected to take 12 minutes to complete, for a total participation of 24 minutes.

- On three days, I will be present at the end of the cafeteria line during school lunch. I will count all the children who choose a vegetable. No identifying information at all will be recorded. This activity will not require anything of your child, nor impact their school lunch in any way.

Your child's participation in this study will help to gauge the effectiveness of the gardening program, and improve it for future use. There is no risk or harm to your child as a result of participating in this evaluation. Your child's educational or lunch experience will not change whether or not you choose to have him or her participate in the evaluation.

All information your child provides will be kept strictly confidential, and any report of the study will not identify your child personally. Only my advisor, Dr. Nancy Cotugna, and I will have access to the information collected.

If you have any questions, we encourage you to ask them. If you want information regarding the study or your child's participation, please contact me at (302) 831-0365. If you have questions about the rights of research participants, you may contact the Chair of the Human Subjects Review Board of the University of Delaware at (302) 831-2136.

Sincerely,

James DiDomenico

University of Delaware, Graduate Student, Health, Nutrition, \& Exercise Science

How to Opt-Out

If you agree to allow your child to participate in the evaluation component of the gardening project, YOU DO NOT NEED TO TAKE ANY ACTION. If, however, you do not want your child to participate, please fill out and sign the form below, and return it to your child's teacher.

I do not want my child evaluation project. (name of child) to participate in the school gardening

\begin{tabular}{cc} 
& \multicolumn{1}{c}{ UNIVERSTYY OF DELAWARE } \\
\hline APPROVED BYHSRB \\
\hline (signature of parent/guardian) & $2125109 \quad 20 \mathrm{P}$ \\
\hline & DATE
\end{tabular}


Appendix B

PRE- AND POST-PROGRAM QUESTIONNAIRE

\section{Today's Date}

Please circle the one answer that best describes you.

1. I am:

Male

Female

2. I am: White

Black

Native American

Asian-American

Other

3. I consider myself to be Hispanic or Latino:

$$
\text { Yes }
$$

No

4. Please circle the names of all the vegetables you have ever tasted, even if you do not like the vegetable.

I have tasted:

Tomatoes Carrots

$$
\text { Peppers }
$$

Kale

Corn

Broccoli

Zucchini

Spinach

Green Beans

Onions

Cucumbers

$$
\text { Radishes }
$$

Peas

Potatoes

Lettuce

Beets

Salad mix

Cabbage

Arugula

Turnips

Squash

Mushrooms Beans

Other, please list 
5. Circle the names of all the vegetables you enjoy eating.

I enjoy eating:

Tomatoes Carrots Peppers Kale Corn

Broccoli Zucchini Spinach Green Beans Onions

Cucumbers Radishes Peas Potatoes Lettuce

Beets Salad mix Cabbage Arugula Turnips

Squash Mushrooms Beans

Other, please list

Circle the answer that best describes you. Please circle only one answer.

6. At School Lunch, I eat vegetables days each week:

No $(0)$ 1 2 3 4

7. If you knew that the vegetables served at School Lunch were grown by classes at your school, would that make you more likely or less likely to eat those vegetables?

$$
\text { More likely Less likely About the same }
$$

8. Have you or your family ever grown vegetables outside of school? Yes No

9. I enjoy eating vegetables.

Always Sometimes Occasionally Never

10. I am willing to try new vegetables. 
Always Sometimes Occasionally Never

11. I am willing to give vegetables I do not like another try.

Always Sometimes Occasionally Never

Thank you for helping us by answering these questions. 